\title{
Formation of Oxide Layers on Aluminum, Niobium, and Tantalum in Molten Alkali Metal Carbonates
}

\author{
E. V. Nikitina* and N. A. Kazakovtseva \\ Institute of High-Temperature Electrochemistry, Ural Branch, Russian Academy of Sciences, \\ Yekaterinburg, 620219 Russia \\ Ural State University, pr. Lenina 51, Yekaterinburg, 620083 Russia \\ *e-mail:neekeetina@mail.ru \\ Received February 1, 2013
}

\begin{abstract}
The electrochemical synthesis of niobium, tantalum, and aluminum oxide nanolayers is studied in the melt of lithium, sodium, and potassium carbonates with various additives to a salt phase in an oxidizing atmosphere at a temperature of 773 and $873 \mathrm{~K}$. A scheme is proposed for high-temperature anion local activation of the process.
\end{abstract}

DOI: $10.1134 / \mathrm{S} 0036029513080119$

\section{INTRODUCTION}

The experimental investigation of corrosion, especially local anionic activation, in molten alkali metal carbonates is hindered by many factors, such as the diversity of the structural elements of high-temperature setups and a difficult experimental observation.

A theory of metal corrosion in molten oxygen-containing salt systems that can take into account the processes occurring at the level of active material microregions is still absent. Moreover, another difficulty consists in the fact that a corrosion product layer, i.e., oxide or halide (depending on an oxidizing agent), can be treated as an ionic crystal. In this case, diffusing substances should move in a film crystal in the form of anions and cations. Therefore, diffusion in this case is related to electric charge transfer, which results in the appearance of an electric field affecting diffusion [1-3]. In addition, film growth is accompanied by partial film dissolution in a salt melt under conditions of significant anodic polarization at an activator ion concentration higher than a certain critical value.

The purpose of this work is to describe the corrosion interaction of an electronegative metallic anode coated with a hard-to-dissolve corrosion product film with a salt phase and to consider the effect of the composition of a high-temperature carbonate electrolyte, into which substances having different chemical nature were artificially added.

The study of the kinetics and mechanism of a corrosion process and a combination of electrochemical methods with the concepts of the chemistry of solids make it possible to predict the electrocatalytic and other properties of metallic and oxide materials.

\section{EXPERIMENTAL}

We studied the interaction of aluminum, tantalum, and niobium with a carbonate eutectic in a high-temperature electrochemical cell in an air atmosphere at 773 and $873 \mathrm{~K}$. The eutectic mixture of lithium, sodium, and potassium carbonates at the ratio $40: 30: 30 \mathrm{~mol} \%$ was prepared from reagent grade salts. The salts were melted in a $\mathrm{CO}_{2}$ atmosphere. The aluminum, tantalum, and niobium samples were $1 \times 1-\mathrm{cm}$ plates cut from a foil. They were processed by an abrasive paper, degreased, and dried by an alcohol-acetone mixture. The carbonate eutectic was charged in a crucible and heated to a given temperature, and a sample was then placed in the melt. The auxiliary electrode was made of a platinum wire and the reference electrode was a carbonate electrode [4].

With anodic chronoamperometry, we can study the oxide film growth rate and the effect of a number of factors on the formation and development of local corrosion damages and collect the amount of oxidation products sufficient for X-ray diffraction (XRD). Potentiostatic investigations were carried out at a fixed potential for $4 \mathrm{~h}$ in a carbonate melt, in which activator ions were introduced after the beginning of polarization, and during steplike potential scanning to the anodic region from a stationary value to $\sim 2 \mathrm{~V}$ in $0.1-\mathrm{V}$ steps at a counting time of $600 \mathrm{~s}$ per step.

Sample surfaces after oxidation were analyzed with a GEOL SM-5900 LV scanning electron microscope. The oxide layer thickness was measured on an AVASOFTThin Film for Ava Spect-2048 FT-2 device.

\section{RESULTS AND DISCUSSION}

During local anion activation of aluminum, tantalum, and niobium, cations and anions from a melt pass to a film and form complex oxides, which is explained 


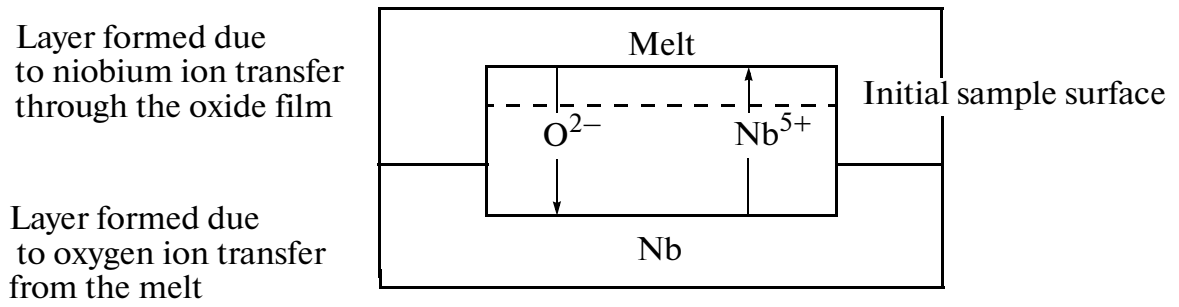

Fig. 1. Scheme for the formation of an oxide layer on niobium (as an example).

by the conduction asymmetry of an anode oxide film, i.e., the so-called valve action.

Free metal ions $\left(\mathrm{Nb}^{5+}, \mathrm{Ta}^{5+}\right)$ are transferred through the forming oxide film, and the film growth caused by these ions takes place only at the internal boundary of the film. On the outer side, the film grows due to oxygen ions $\mathrm{O}^{2-}$ from the melt. Thus, the ratio of inner layer thickness $\delta_{\text {in }}$ to outer layer thickness $\delta_{\text {out }}$ can be determined in terms of the transport number of $M^{n+}$ and $\mathrm{O}^{2-}$. If we assume that the density of the inner layer is the same as that of the outer layer, this ratio for niobium is $\delta_{\text {in }} / \delta_{\text {out }}=3.0$ [5]. Thus, the interface between the inner and outer parts of the layer is located at the initial surface in the initial stage of anodizing and moves toward the interface with the melt as the film thickness increases (Fig. 1). The film composition is a function of the distance from the initial interface. The anodic oxide film near the interface with the melt is saturated with oxygen and mainly contains higher niobium and tantalum oxides $\left(\mathrm{Nb}_{2} \mathrm{O}_{5}, \mathrm{Ta}_{2} \mathrm{O}_{5}\right)$, oxides with a lower valence are present near the oxide film-metal interface, and the total composition of the oxide film can be represented as $\mathrm{Nb}_{2} \mathrm{O}_{5 x}$ and $\mathrm{Ta}_{2} \mathrm{O}_{5 x}$ and $\mathrm{Al}_{2+x} \mathrm{O}_{3}$ for aluminum [6].

The results of studying aluminum demonstrate that the component contents in the film correspond to empirical formula $M \mathrm{Al}_{x} \mathrm{O}_{y}$, where $M$ is an alkali metal, $x=1.5-2.2$, and $y=1.8-2.8$. As the temperature increases, $x$ and $y$ decrease but the ratio $x: y$ remains almost the same. We assume that aluminum oxide interacts with molten carbonates to form aluminates. The film growth rate in the temperature range under study is $3-5 \mathrm{~nm} / \mathrm{h}$ [7].

Niobium and tantalum oxides also interact with the carbonate melt to form tantalates and niobates,

$$
\begin{gathered}
\mathrm{Nb}_{2} \mathrm{O}_{5}+M_{2} \mathrm{CO}_{3}=2 M \mathrm{NbO}_{3}+\mathrm{CO}_{2}, \\
\mathrm{Ta}_{2} \mathrm{O}_{5}+M_{2} \mathrm{CO}_{3}=2 M \mathrm{TaO}_{3}+\mathrm{CO}_{2},
\end{gathered}
$$

where $M$ is an alkali metal ( $\mathrm{Li}, \mathrm{Na}, \mathrm{K})$.

The films do not undergo total dissolution, since both alkali metal ions from the melt and oxygen ions migrate through these films.
If the oxide film density is assumed to be constant throughout the volume, the Pilling-Bedworth ratio is calculated as

$$
R_{M}=\frac{V_{\mathrm{oks}}}{V_{M}}=\frac{M_{\mathrm{ox}} / \rho_{\mathrm{ox}}}{M_{M} / \rho_{M}}
$$

where $V_{\mathrm{ox}}$ is the forming oxide volume, $V_{M}$ is the metal volume involved in oxide formation, $M_{\text {ox }}$ is the molecular mass of the oxide $\left(M_{\mathrm{Nb}_{2} \mathrm{O}_{5}}=266 \mathrm{~g} / \mathrm{mol}\right), M_{M}$ is the molecular mass of the metal $\left(M_{\mathrm{Nb}}=92.9 \mathrm{~g} / \mathrm{mol}\right), \rho_{\mathrm{ox}}$ is the forming oxide density $\left(\rho_{\mathrm{Nb}_{2} \mathrm{O}_{5}}=4.5 \mathrm{~g} / \mathrm{cm}^{3}\right)$, and $\rho_{M}$ is the metal density $\left(\rho_{\mathrm{Nb}}=8.57 \mathrm{~g} / \mathrm{cm}^{3}\right)$ [2]. This ratio is $R_{\mathrm{Ta}}=2.4$ for titanium nickelide and $R_{\mathrm{Al}}=1.7$ for aluminum. These values demonstrate that the interface between the inner and outer layers of the anodic oxide film on tantalum is located above the initial surface of the tantalum sample and moves toward the interface with the melt, since the film becomes thicker. In aluminum, the interface between the inner and outer layers lies on the initial surface of the sample.

In addition, the Pilling-Bedworth ratios show that the anodic oxide films formed on all three metals are continuous, since $R_{M}>1$. This indicates the ability of the films to retard further metal oxidation.

The calculated film thicknesses correspond to the experimental thicknesses, $(3-5) \times 10^{-8} \mathrm{~mm}$ (see table).

During local anion activation of aluminum, an oxide film grows in a manner identical to that on tantalum and aluminum and it also undergoes partial dissolution mainly due to direct passage of aluminum ions into the melt. Only an insignificant fraction of aluminum ions passes to the melt as a result of the dissolution of aluminum oxide.

It was found that the rate of increase of the number of pittings on the metals surfaces under study is inversely proportional to time and the rate of their "healing" is directly proportional to their number. This behavior is described by the formula

$$
\frac{d \xi}{d \tau}=\frac{\sigma}{\tau}-\kappa \xi(\tau)
$$

where $\xi$ is the number of pittings, $\tau$ is the time $(0<\tau<T)$, $\kappa$ is the coefficient $(0<\kappa<1)$, and $\sigma=\sigma(U, N, T)$ is a 
Table

\begin{tabular}{|c|c|c|c|c|c|}
\hline \multirow{2}{*}{ Metal } & \multicolumn{2}{|c|}{ Film thickness $h, \mathrm{~mm}$} & \multirow{2}{*}{$\begin{array}{l}\text { Corrosion rate, } \\
\mathrm{g} /\left(\mathrm{m}^{2} \mathrm{~h}\right)\end{array}$} & \multirow{2}{*}{$\begin{array}{c}\text { Corrosion } \\
\text { current } i, \mathrm{~mA}\end{array}$} & \multirow{2}{*}{$\begin{array}{c}\text { Activation energy } E^{a}, \\
\mathrm{~J} / \mathrm{mol}\end{array}$} \\
\hline & calculated & measured & & & \\
\hline A1 & $10^{-9}$ & $2 \times 10^{-9}$ & 4.8 & -0.6 & 14.3 \\
\hline $\mathrm{Nb}$ & $2 \times 10^{-8}$ & $2 \times 10^{-8}$ & 15.7 & -0.9 & 75 \\
\hline $\mathrm{Ta}$ & $10^{-8}$ & $1.5 \times 10^{-8}$ & 12.3 & -0.7 & 70 \\
\hline
\end{tabular}

function of the system parameters ( $U$ is the voltage, $N$ is the activator content, $T$ is the holding time).

An analysis of this equation provided that pittings are absent on a sample at the initial time shows that the number of pittings is maximal $10-15 \mathrm{~min}$ after the beginning of the experiment and that their number decreases slowly with time.

Current $I$ passing through a halide complex increases with corrosion damage radius $r$, since the current passing from the substrate mainly concen-

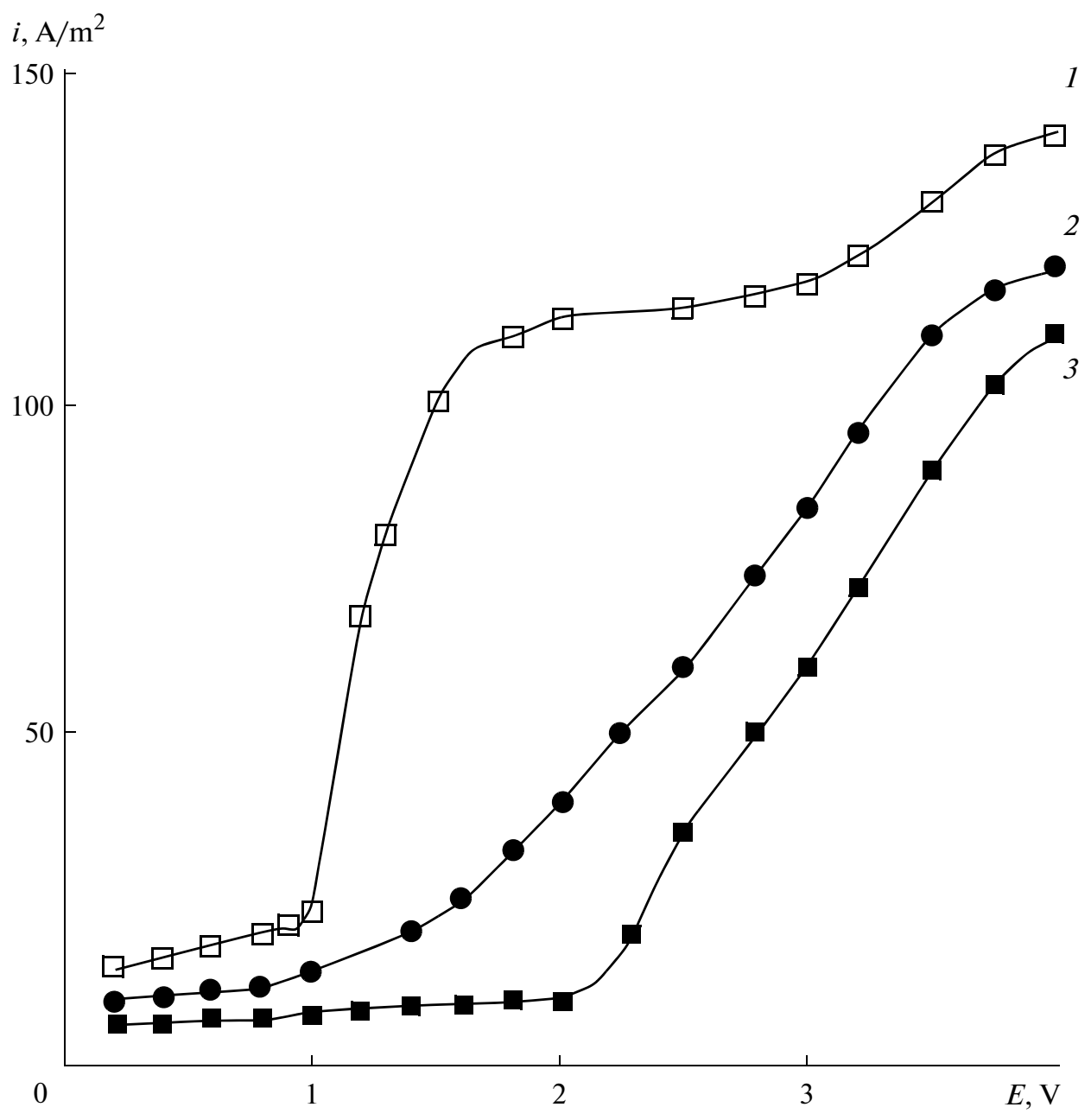

Fig. 2. Anodic polarization curve for aluminum with $\mathrm{NaCl}$ (mol \%) added to a carbonate melt: (1) 3.4, (2) 2.5 , and (3) 1 . 


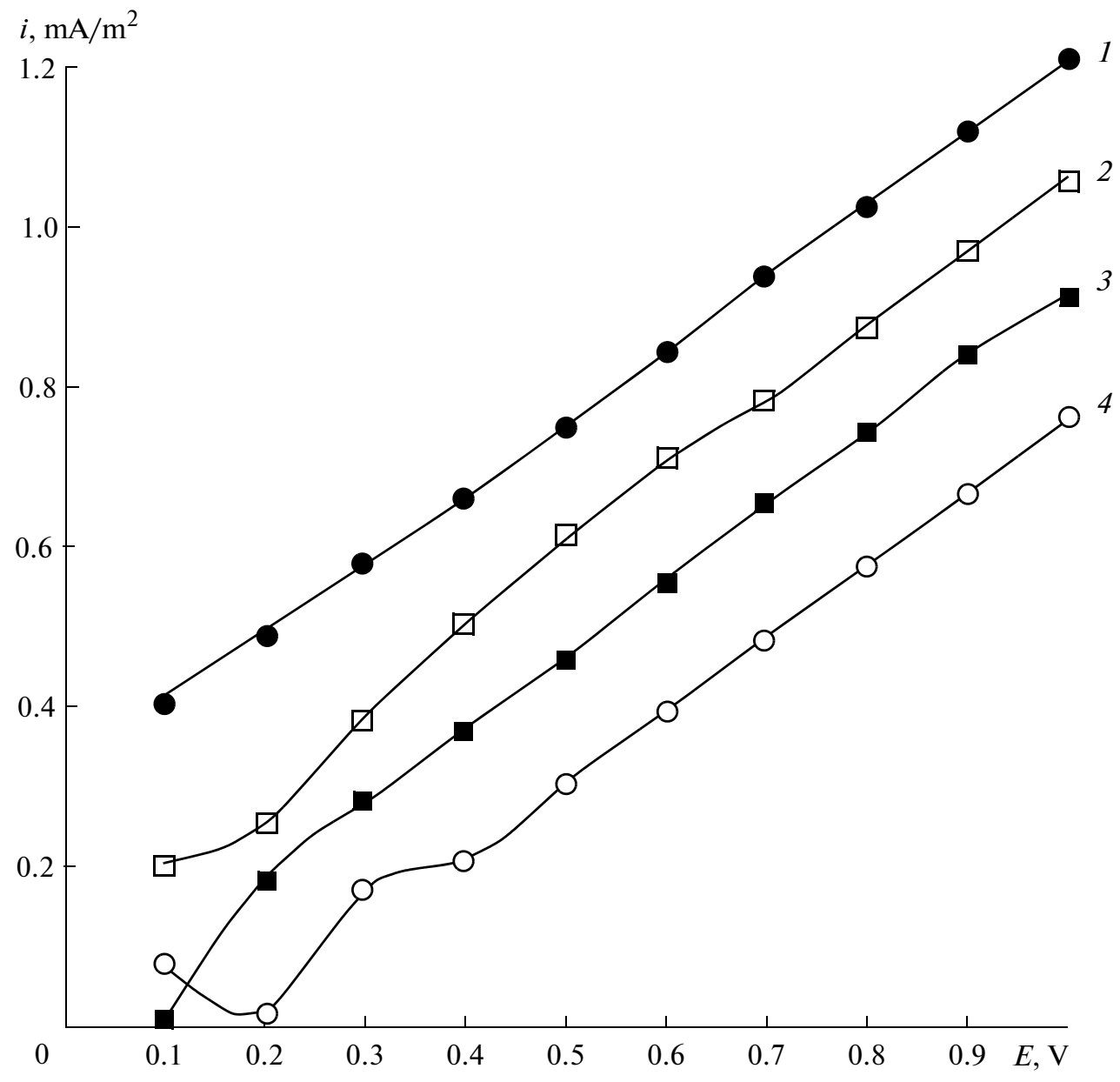

Fig. 3. Anodic polarization curve for tantalum for a carbonate melt with (1) $\mathrm{NaNO}_{3}$ and $\mathrm{NaCl}$, (2) $\mathrm{KOH}$, (3) without additives, and (4) $\mathrm{LiNO}_{3}$.

trates in the halide complex because of the high resistance of the anodic oxide film,

$$
I=2 \pi r^{2} N S K \exp \left(\frac{\beta F \Delta \Phi}{R T}\right)
$$

where $N$ is the total number of chloride ions per unit surface, $S$ is the sample area, $K$ is the constant determining the chemical nature, and $\beta$ is the coefficient $\beta=\alpha z+n \alpha_{1}\left(n=1, \ldots, N_{\mathrm{s}}\right)$. We can write

$$
I=A \pi r^{2} N S K,
$$

where $A$ is the dissolution current expressed empirically in terms of potential $E$ and chloride ion concentration $C_{x}$,

$$
A=k_{x} C_{x}^{n} \exp \left(-\xi \frac{F E}{R T}\right)
$$

where $k_{x}, n=$ const.
The corrosion damage size was calculated by the formula

$$
r=\sqrt{I / A \pi N S} .
$$

The process of anodic activation begins when a certain well reproduced potential (pitting formation potential) is reached and results in a sharp increase in the anode current (Figs. 2, 3). The higher the chloride ion concentration, the lower the potential of the onset of pitting formation.

As the potential increases, the pitting formation potential is also the breakdown potential of film due to chloride ions. However, a significant hysteresis is observed in the reverse run of the polarization curve, and pittings are repassivated at the potential that is equal to the stationary potential before the beginning of polarization [4]. A passivator $\left(\mathrm{Na}_{2} \mathrm{O}_{2}, \mathrm{KOH}\right)$ improves the corrosion resistance of a metal by passivating defects in the outer layer of the oxide film. 

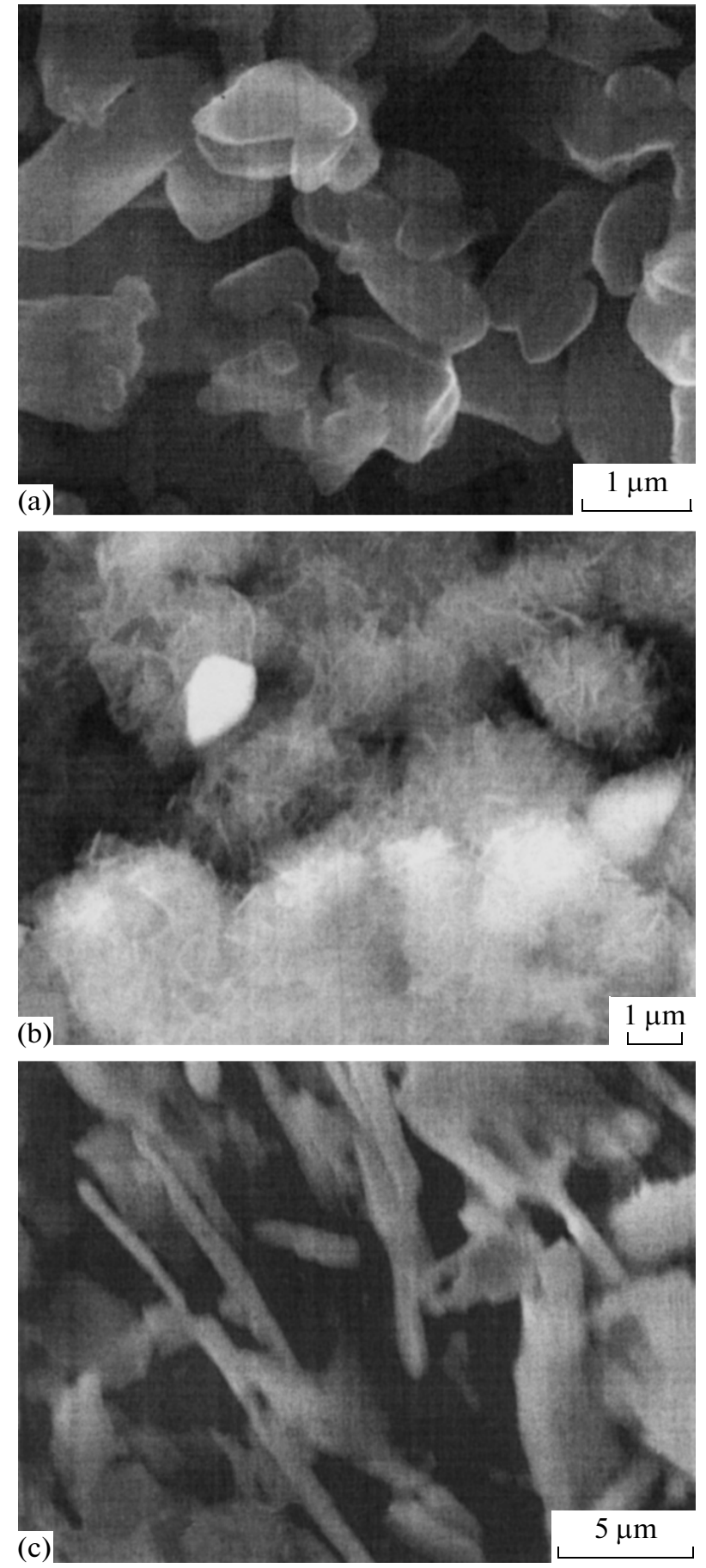

Fig. 4. Micrograph of the (a) aluminum, (b) niobium, and (c) tantalum surface after anodic polarization in a carbonate melt.

In the experiments on tantalum and niobium, we detected the same dependence as in the experiments on aluminum. When halide ions are added to a carbonate melt, the potential shifts to the region of electronegative values and pitting formation begins at a lower potential as compared to the experiment performed with a pure carbonate melt without additives.
Temperature only weakly affects the process, although the oxide film growth rate slightly increases and the current density somewhat decreases with increasing temperature.

The micrograph of the aluminum surface in Fig. 4a exhibits a very dense layer of corrosion products, which consists of individual crystals of different sizes that are randomly arranged with respect to each other and are connected by bridges at some sites (Fig. 4a). The niobium surface is seen to be nonuniform, with local individual corrosion damages (Fig. 4b). The tantalum surface is coated with needlelike corrosion products arranged normal to the surface (Fig. 4c). On the whole, the layer is continuous, without visible corrosion damages.

\section{CONCLUSIONS}

(1) When valve metals undergoes anodic oxidation, amorphous oxide films with a complex composition mainly form and the reaction occurs due to the diffusion of reacting substances through an oxide film.

(2) The structure and properties of the protective layers on valve metals depend on their formation conditions, namely, the temperature, the polarization potential, and the electrolyte composition.

(3) Oxygen-containing layers of the following two types can be formed on valve metals in the eutectic melt of lithium, sodium, and potassium carbonates: thick porous layers or thin dense films.

\section{REFERENCES}

1. V. N. Chebotin, Transfer Phenomena in Ionic Crystals (Izd. UrGU, Sverdlovsk, 1968).

2. L. L. Odynets, Physics of Oxide Films. A Course of Lectures. Part 1 (Izd. PGU, Petrozavodsk, 1979).

3. Physics of Thin Films, Ed. by M. Francombe and R. Hoffman (Academic Press, New York, 1969), Vol. 6.

4. E. V. Nikitina, T. I. Manukhina, V. I. Sannikov, and V. Ya. Kudyakov, "Kinetics of pitting formation on aluminum in a melt of alkali metal carbonates containing chloride ions," Elektrokhimiya 33 (12), 1419-1422 (1997).

5. K. Nagahara and M. Sakairi, "Mechanism of formation and growth of sunflower-shaped imperfections in anodic oxide films on niobium," Electrochemical Acta 52, 2134-2145 (2007).

6. T. I. Manukhina, I. N. Ozeryanaya, B. D. Antonov, and V. P. Chernyshev, "Anodic polarization of aluminum in molten alkali metal carbonates," in Transactions of Institute of Electrochemistry UNTS SSSR (Sverdlovsk, 1978), Vol. 26, pp. 43-47.

7. V. I. Sannikov, T. I. Manukhina, and K. A. Stepanov, "On the oxide films on aluminum grown in molten alkali carbonates," Zashch. Met. 24, 492-494 (1988).

Translated by K. Shakhlevich 